Article

\title{
High-Resolution Structure-from-Motion for Quantitative Measurement of Leading-Edge Roughness
}

\author{
Mikkel Schou Nielsen ${ }^{1, *(\mathbb{D}}$, Ivan Nikolov ${ }^{2}{ }^{\mathbb{D}}$, Emil Krog Kruse ${ }^{3}$, Jørgen Garnæs ${ }^{1}$ \\ and Claus Brøndgaard Madsen ${ }^{2}$ (D) \\ 1 Danish Fundamental Metrology, Kogle Allé 5, DK-2970 Hørsholm, Denmark; jg@dfm.dk \\ 2 Department of Architecture, Design and Media Technology, Aalborg University, Rendsburggade 14, \\ DK-9000 Aalborg, Denmark; iani@create.aau.dk (I.N.); cbm@create.aau.dk (C.B.M.) \\ 3 Power Curve ApS: Kastetvej 2, DK-9000 Aalborg, Denmark; ekk@powercurve.dk \\ * Correspondence: msn@dfm.dk
}

Received: 19 June 2020; Accepted: 24 July 2020; Published: 31 July 2020

\begin{abstract}
Over time, erosion of the leading edge of wind turbine blades increases the leading-edge roughness (LER). This may reduce the aerodynamic performance of the blade and hence the annual energy production of the wind turbine. As early detection is key for cost-effective maintenance, inspection methods are needed to quantify the LER of the blade. The aim of this proof-of-principle study is to determine whether high-resolution Structure-from-Motion (SfM) has the sufficient resolution and accuracy for quantitative inspection of LER. SfM provides 3D reconstruction of an object geometry using overlapping images of the object acquired with an RGB camera. Using information of the camera positions and orientations, absolute scale of the reconstruction can be achieved. Combined with a UAV platform, SfM has the potential for remote blade inspections with a reduced downtime. The tip of a decommissioned blade with an artificially enhanced erosion was used for the measurements. For validation, replica molding was used to transfer areas-of-interest to the lab for reference measurements using confocal microscopy. The SfM reconstruction resulted in a spatial resolution of $1 \mathrm{~mm}$ as well as a sub-mm accuracy in both the RMS surface roughness and the size of topographic features. In conclusion, high-resolution SfM demonstrated a successful quantitative reconstruction of LER.
\end{abstract}

Keywords: structure from motion; surface analysis; leading-edge roughness; blade inspection; quantitative $3 \mathrm{D}$ reconstruction; photogrammetry

\section{Introduction}

Erosion of wind turbine blades poses a challenge for wind energy operation and maintenance [1]. Erosion of the leading edge (LE) increases the surface roughness and reduces the aerodynamic performance of the blade [1,2]. As the shape of wind turbine blades is specifically designed to achieve maximum energy efficiency [3], this increased leading-edge roughness (LER) may lead to a reduced annual energy production of the wind turbine. Through CFD modelling, several studies have found that even a small degree of LE erosion can lead to 2-5\% loss in annual energy production [4-6]. Severely eroded blades with high levels of LER can experience losses from $8 \%$ and up to $25 \%[4,7,8]$. As LE erosion over time can develop from small pinholes to large areas of coating delamination $[4,9]$, early detection of the severity of the erosion is important. At later erosion stages, extensive blade repair may be necessary causing expensive turbine downtime. Thus, for early erosion detection, inspection methods for measuring the surface topography of the blade are needed to quantify the LER. 
Visual inspection has long been applied for condition-monitoring of wind turbine blades [10]. In recent years, unmanned aerial vehicles (UAV) have received increased interest for remote inspection of wind turbines [11-16] with a lower downtime compared to manual rope-access inspection. From 2D images captured by the UAV, deep learning methods $[13,15]$ can be used for detecting damages and erosion on the blades. However, while the 2D information can reveal the presence and location, quantification of the blade surface roughness requires high-resolution 3D data.

Structure-from-Motion (SfM) is a camera-based method that provides a 3D reconstruction of an object geometry with a simple, fast and low-cost acquisition [17-19]. Aided by a rapid development of both open source [20,21] and commercial software solutions [22-24], SfM has found industrial interest in e.g., construction site monitoring [25-27] and infrastructure inspection [28-32]. A lot of research has also been done in the performance of SfM, for different use cases [33,34]. As input for the SfM reconstruction, overlapping images of the object from different positions and orientations are acquired using an RGB camera. Feature points are extracted and matched between the 2D input images using local feature descriptors such as SIFT [35] or ORB [36]. From the feature points and intrinsic camera parameters, a sparse 3D point cloud as well as the camera positions and orientations are computed. Using information from reprojected camera views, further points can be added to create a dense point cloud, which can be further meshed [37,38].

The accuracy of a SfM reconstruction is influenced by several factors. Since SfM depends on triangulation of feature points, the accuracy is affected by the angular coverage of the acquired images [19,39] and scales with the capturing distance from camera to object $[38,40,41]$. Furthermore, a sufficient texture level is required for enough distinct features on the object surface to be tracked from image to image [19,42]. Low texture regions may result in empty regions of the point cloud [43]. To evaluate the accuracy, the SfM reconstruction is typically compared to another optical technique such as a LiDAR or laser scanner. This can be done either by direct point-to-point comparison with the SfM point cloud [19,44,45] or raster-to-raster comparison of digital elevation models (DEM) $[46,47]$. Either way, the comparison is influenced by the measurement uncertainty of the reference points [47]. Common metrics for reporting the accuracy are the standard deviation (SD) $[17,33,44]$ and root mean square deviation (RMSD) [41,43,46].

Within wind energy, SfM has previously been investigated for 3D reconstruction of blade geometries [11,16]. However, these studies did not have a sufficient resolution to reconstruct the surface topography directly and rather used the color texture to identify damages. With high-resolution $\mathrm{SfM}$, a point-sampling distance below $0.1 \mathrm{~mm} /$ pixel can be achieved which allows for reconstruction of the surface roughness [48,49].

In this proof-of-principle study, we investigate the potential of high-resolution SfM in quantitative inspection of wind turbine blades. We envisage a scenario where an UAV carrying a high-end RGB camera is capturing images of the LE of blades. Using these images, a SfM reconstruction of (parts of) the LE is performed from which quantitative measures of the LER can be extracted. The study seeks to answer two main questions. First, to demonstrate whether a sufficient resolution can be achieved to reconstruct the LER of a blade. Secondly, what is the performance of high-resolution SfM in providing quantitative measures of the surface topography of the LER. A mock-up of an eroded blade was fabricated by artificially enhancing the LER of the tip of a decommissioned blade. The SfM capturing was done using a handheld camera and in an outdoor environment to mimic realistic inspection conditions. In the high-resolution acquisition, the images were acquired from a distance of roughly $2 \mathrm{~m}$ using a $300 \mathrm{~mm}$ lens. We believe these conditions to be representative of what the envisaged UAV inspection scenario might operate with.

For evaluating the accuracy of the SfM reconstruction, selected areas on the blade surface were extracted from the point cloud and converted to a DEM. Replicas of the same areas on the blade surface were made using replication molding and transferred to the lab. Replication molding is a demonstrated method for transferring hard-to-access surface topographies to a substrate suitable for microscopy measurements [50]. In the replication of surface roughness, accuracies at the sub-micrometer level 
have been demonstrated using elastomer replica materials [51-56]. Using confocal microscopy (CM) measurements of the replicas, a DEM was created for direct raster-to-raster comparison to the SfM reconstruction. The resolution of the SfM reconstruction was evaluated using Fourier analysis and RMSD calculation. For validation of the resolution analysis, a model was constructed by reducing the resolution of the reference DEM and adding noise. This model DEM was then compared to the SfM DEM. Finally, the quantitative performance in measuring LER was evaluated using surface roughness parameters and topographic feature sizes.

\section{Methods and Materials}

\subsection{Blade Mock-up}

A decommissioned wind turbine blade was available for the experimental setup. The blade had been used in a modern $2 \mathrm{MW}$ pitch-regulated wind turbine. Span-wise, the outer two meters of the blade that already had some erosion was used. To better resemble the examples of severe LE erosion experienced from field inspections $[4,8,9]$, the erosion was artificially increased by sandblasting the LE. At this level of erosion, large areas of laminate are exposed along the LE with depths of 1-3 mm. Severe erosion was chosen for this study for two main reasons. First, depths of these magnitude are at the order where the aerodynamic performance is significantly impacted. A study by [57] found that the critical height of roughness for lowering the maximum lift of wind turbine blades was above $1 \mathrm{~mm}$. Secondly, a large surface roughness represents a good pass/fail test of the feasibility of high-resolution SfM. If the resolution was not sufficient for resolving large erosion structures, it would not function for less eroded surfaces either.

For inspection of a wind turbine in operation, we envision that the turbine is stopped with the inspected blade in a vertical position. To simulate this, the blade was mounted vertically in a gantry, which was welded together for the purpose of this work. To include the effect of oscillations, chain links were used to fix the blade mock-up to the gantry, which let the blade segment move freely in the wind. The height of the gantry was $5 \mathrm{~m}$, resulting in a distance of $5 \mathrm{~m}$ from the very tip of the blade to the ground. The blade setup on the gantry, together with the scissor lift used to capture all the data for this paper can be seen in Figure 1.

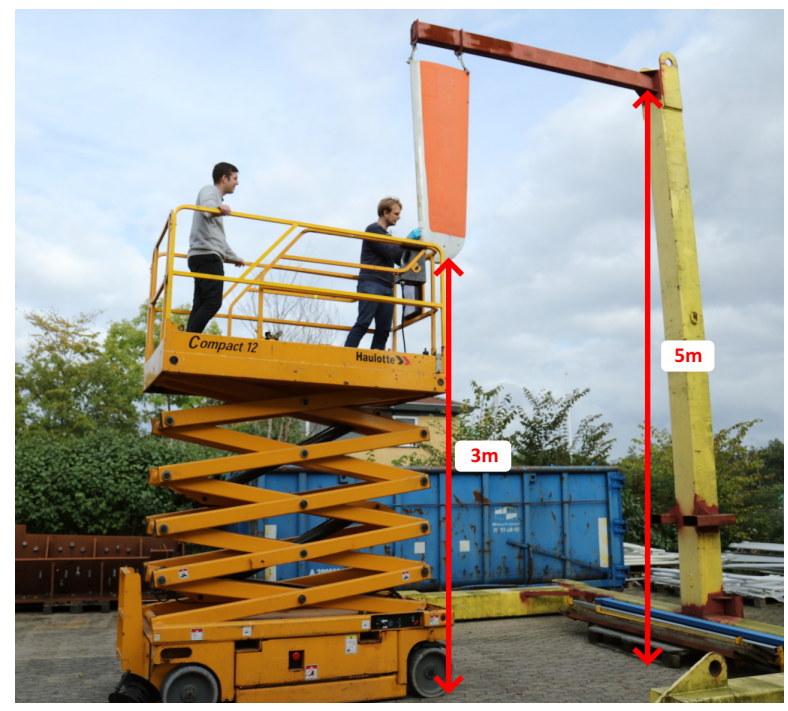

Figure 1. The wind turbine blade segment positioned on the built gantry, together with the scissor lift used for capturing image and replica data.

\subsection{SfM Capturing Conditions}

The image capturing process of the proof-of-principle study was done in an outdoor environment to ensure realistic capturing conditions. A commercial DSLR camera (Canon 5Ds) with a variable 
zoom lens (Canon 70-300 f/4-5.6L IS USM) was used with the focal length fixed at $300 \mathrm{~mm}$. Camera parameters and settings are summarized in Table 1 . As the capturing was done outdoors, a number of prerequisites need to be taken into account:

- The natural illumination can change between images.

- The sides of the blade mock-up may not be evenly illuminated.

- Wind can cause oscillations of the blade mock-up, which can change its position and orientation compared to previous images.

Since the accuracy of the SfM reconstruction depends on the stability of light conditions, camera settings should be robust to environmental changes in light direction and intensity. In addition, the settings should take into account the possible motion of the blade. The chosen ISO, shutter, and aperture settings are shown in Table 1. They represent what we believe to be reasonable compromises between exposure for outdoor conditions, becoming less sensitive to motion blur (shutter) and not having to worry too much about too shallow depth-of-field (aperture).

Table 1. Camera parameters and settings for the outdoor capturing setup.

\begin{tabular}{ll}
\hline Camera Parameters & Values \\
\hline ISO & 800 \\
Shutter Speed [sec] & $1 / 200$ \\
Aperture & $\mathrm{f} / 16$ \\
Focal length [mm] & 300 \\
Image size [pixels] & $8688 \times 5792$ \\
Sensor pixel size [ $\mu \mathrm{m}]$ & 4.14 \\
\hline Capturing Setup & \\
\hline Distance to blade $[\mathrm{m}]$ & 2 \\
Angular spacing [ $\left.{ }^{\circ}\right]$ & 10 \\
Capturing bands & 3 \\
No of images & 57 \\
GSD [ $\mu \mathrm{m} /$ pixel] & 27 \\
\hline
\end{tabular}

For the initial proof-of-principle study, a manual and handheld image capturing was performed. A part of the wind turbine blade was chosen that contained a variation in surface topography across the leading edge; from very rough damaged areas to smoother clean areas. The part of the blade chosen for 3D reconstruction is shown in Figure 2.

A semi-circular 180-degree capturing pattern was used for the image capturing. This capturing method was shown by $[34,58]$ to produce high accuracy reconstructions while also minimizing the number of required images. Three horizontal semi-circular bands each with 19 images were acquired giving a total of 57 images. To ensure enough vertical separation between the horizontal bands, the first band was taken from the ground level looking toward the suspended blade. To capture the other two bands a moving scissor lift was used. The captured positions can be seen in Figure $3 \mathrm{~b}$. This way the blade surface could be captured from different positions and angles both in horizontal and vertical direction, ensuring maximum cover. The semi-circles were centered around the wind turbine blade with a distance of $2 \mathrm{~m}$ from camera to blade. The capturing settings are summarized in Table 1.

For a fixed focal length, the capturing distance determines the ground sampling distance (GSD), i.e., the spatial size on the object that each pixel in a captured image covers. Using a pinhole camera model, the GSD can be calculated as the camera sensor pixel size $p$ multiplied by the ratio of the distance between camera and surface $D$ over the focal length $f$ as shown in Equation (1).

$$
G S D=\frac{D}{f} p
$$


With the used settings in the study, the GSD was $27 \mu \mathrm{m} /$ pixel which corresponds to approximately 36 pixels $/ \mathrm{mm}$ on the blade surface.

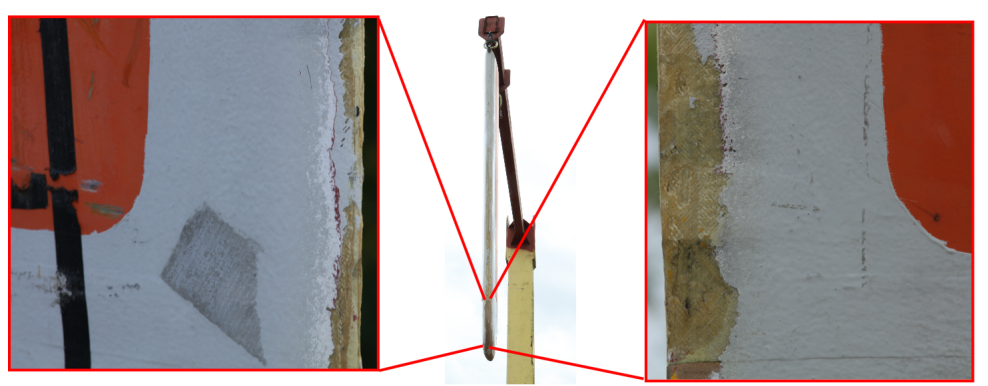

Figure 2. Testing blade together with the region chosen for reconstruction. The zoomed-in parts are of the two sides of the blade.

(a) Input images
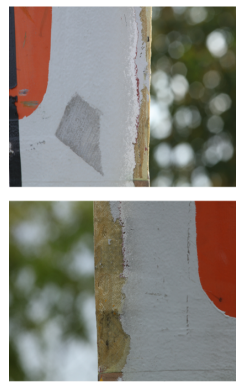

(d) Reconstruction in color

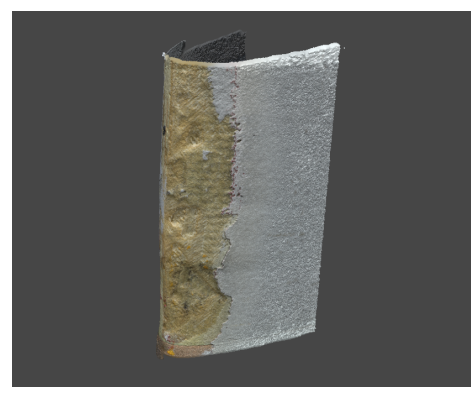

(b) Camera pose

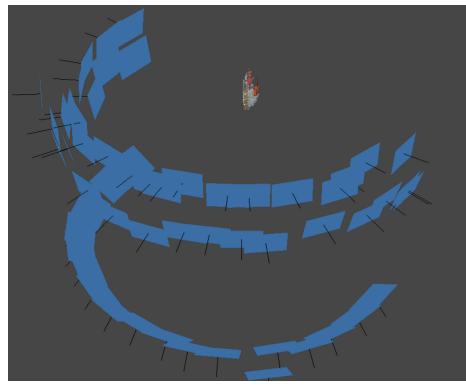

(e) Patch in color

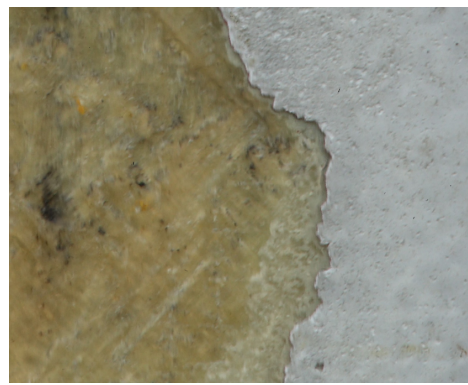

(c) Reconstructed 3D geometry

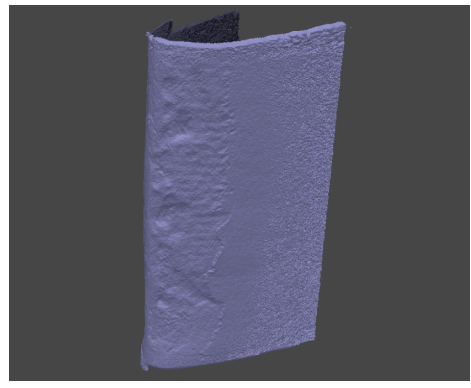

(f) DEM of patch

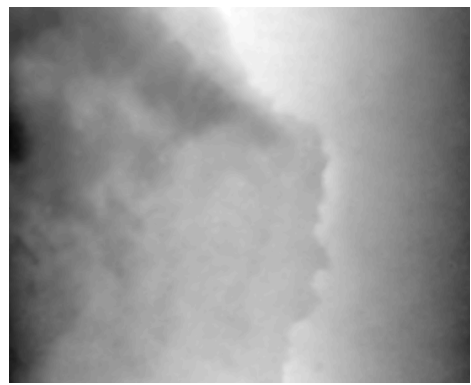

Figure 3. Pipeline for 3D reconstruction using SfM. (a) Initially, images were acquired at every 10 degrees of a half circle around the wind turbine blade at three different heights and tilt angles. (b) The camera pose of the images and points on the object surface were then calculated. The reconstructed surface geometry without (c) and with color (d). Extracted patch from the reconstruction shown as (e) (color) texture and (f) resulting DEM.

\subsection{SfM Reconstruction}

For SfM reconstruction, the commercial stand-alone software package Agisoft Metashape by [22] was used. It was selected as it has previously demonstrated a high accuracy compared to other state of the art solutions, while being robust against sub-optimal capturing conditions [34]. The pipeline from input images, 3D reconstruction and extraction of depth map patches is visualized in Figure 3. An overview of the process is given below.

The captured images Figure 3a were imported to Metashape and a triangulation, feature extraction and matching step were performed to find the camera positions and key feature points from the input images Figure 3 b. From these positions and feature points, a sparse point cloud was formed. Next in 
the reconstruction process a dense point cloud was created and meshed into a triangle mesh Figure 3c. Finally, a (color) texture was built from the visual data from the input images Figure 3d.

To establish an absolute scale in the SfM reconstruction, the known camera positions and distance from camera to blade surface were used. The method presented in [59] was followed. The scale was calculated using a least-squares transformation estimation between the reconstructed camera positions and the manually measured positions in the real world.

For evaluating the SfM reconstruction, three areas R1, R2 and R3 were selected for comparison to reference microscopy measurements. The areas were chosen to include distinctive surface topography features and cover the boundary between intact coating and damaged surface. For each area, a digital elevation model (DEM) was created from the reconstruction using the following pipeline. First, for further processing and analysis of the mesh the reconstruction was imported to the software CloudCompare [60]. For each area, a patch of roughly $35 \mathrm{~mm} \times 35 \mathrm{~mm}$ was created from the main reconstructed point cloud. The patches were oriented with the Z-axis perpendicular to the mesh surface, and were rasterized into a DEM of the surface topography Figure $3 \mathrm{f}$. This was done by an interpolation of the point-cloud points to a map with equidistant point spacing and using the average $z$-values of each grid space. The resulting pixel size was chosen to be $13.3 \mu \mathrm{m}$ to match the reference microscopy images.

\subsection{Replica Molding}

Replication was performed for each of the R1, R2 and R3 areas described in Section 2.3. As a replication material with a fast curing time and resolution down to $0.1 \mu \mathrm{m}$, RepliSet T3 by Struers [61] was selected. In previous studies, the replication of surface textures using RepliSet has achieved a sub-micrometer accuracy [55,62]. The RepliSet T3 is a black two-part silicone rubber which consists of a polymer and curing agent. For replication, the two parts were pushed out of the cartridge, mixed in a static-mixing nozzle and applied onto the blade surface Figure 4a. Immediately after application, backing paper was placed on top of the mixture and attached by applying a small force as shown in Figure $4 \mathrm{~b}$. The mixture set for $15 \mathrm{~min}$ and then the replica was removed from the blade surface by hand.

(a)

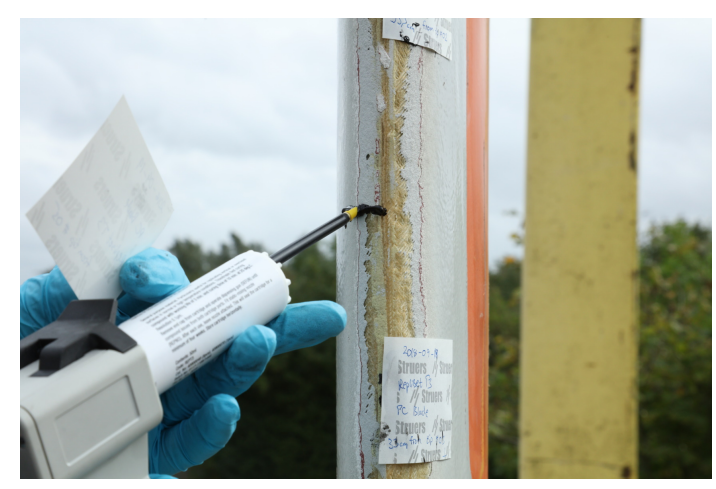

(b)

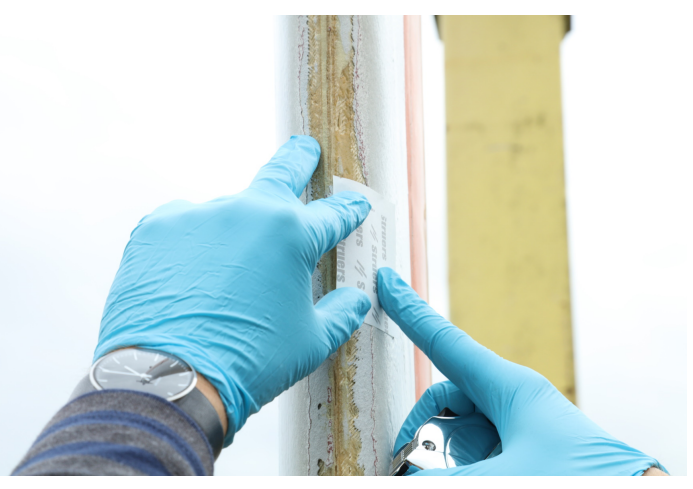

Figure 4. Replication of an area on the blade mock-up. (a) illustrates the application of the combined polymer and curing agent from a static-mixing nozzle. (b) shows the backing paper being attached by applying a gentle force to the replication material.

\subsection{Confocal Microscopy}

Confocal microscopy (CM) was used to produce reference DEMs of the R1, R2 and R3 areas. The three replica of the blade surface were measured using a calibrated PLU NEOX confocal microscope by Sensofar [63]. For each replica, an extended area of approx. $35 \mathrm{~mm} \times 35 \mathrm{~mm}$ was measured by 
stitching around 400 individual images. A x 5 magnification objective with an NA of 0.15 was used. For each image, a $4 \times 4$ binning was used resulting in a final pixel size of $13.3 \mu \mathrm{m}$. To ensure a superior resolution for the CM measurement, the pixel size was kept smaller than the GSD of the SfM reconstruction. The vertical step size (z-axis) used was $12 \mu \mathrm{m}$. The 3D surface reconstruction, stitching and creation of a DEM were performed using the proprietary SensoSCAN software.

The sensitivity of the CM microscope in the vertical direction (z-axis) was calibrated using a set of step height transfer standards. Traceability was ensured through calibration of the standards by e.g., an AFM equipped with laser interferometer. The amplification coefficient of the $z$-axis had a relative uncertainty lower than $3 \%$.

\subsection{Image Processing and Data Analysis}

The main software programs used for the surface topography analysis were the Scanning Probe Image Processor (SPIP) [64] Version 6.6.3 as well as custom scripts in MATLAB version 2019b. SPIP is an image processing program with special tools for accurate characterization of image structures.

Initially using SPIP, each SfM and reference DEM were levelled by subtracting a least-squares parabola fit from the overall shape. This way the long wavelength curvature of the surface was removed, while the short-wavelength surface roughness could be preserved. Then for each area, the SfM DEMs were co-registered using a Fourier correlation approach in MATLAB.

From the co-registered DEMs, geometrical quantities were extracted from both SfM and microscopy reference. The chosen quantities are the depth and height of topographic features.

\subsubsection{SfM Reconstruction Quality}

To evaluate the quality of the SfM reconstruction, two parameters were chosen; The instrument transfer function at $50 \%$ value (ITF50) and the maximum value of the cross-correlation function $\left(\mathrm{CCF}_{\max }\right)$.

The ITF50 value is a measure of the spatial sharpness, which is analogous to the MTF50 value of the modulation transfer function. ITF50 is found as the spatial wavelength at which the instrument response is half the value of the reference. The definition of ITF is shown in (2) [65]. For the calculation, a region on the surface containing a height is selected. For each line across the height step, the ratio of the 1D Fourier transforms of the instrument function and reference is calculated. The ITF is found as the mean of all lines in the region.

$$
\operatorname{ITF}(f)=\left\langle\frac{\left|\int_{-\infty}^{\infty} z(x, y) e^{-i 2 \pi f x} d x\right|}{\left|\int_{-\infty}^{\infty} z_{r e f}(x, y) e^{-i 2 \pi f x} d x\right|}\right\rangle_{y}
$$

$\mathrm{CCF}_{\max }$ has a value between 0 and 1 and describes the spatial similarity of a set of co-registered measurement and reference topographies. If the measurement is very close to the reference, the value of $\mathrm{CCF}_{\max }$ will be close to $1 . \mathrm{CCF}_{\max }$ is found as the maximum of the normalized 2D cross-correlation function [66].

$$
f_{C C F}\left(t_{x}, t_{y}\right)=\frac{\iint_{A} z(x, y) z_{r e f}\left(x-t_{x}, y-t_{y}\right) d x d y}{\sqrt{\iint_{A} z^{2}(x, y) d x d y \iint_{A} z_{r e f}^{2}(x, y) d x d y}}
$$

\subsubsection{Surface Roughness}

Prior to performing the surface roughness analysis, an S-filter of $25 \mu \mathrm{m}$ and an L-filter of $10 \mathrm{~mm}$ were applied to the DEM in accordance with [67]. A plane was chosen as reference surface using a least-squares linear fit to the height values of the DEM. The following areal surface roughness parameters as described in [68] were calculated: $S_{q}, S_{d q}$ and $S_{a l}$. These parameters were chosen as they describe different and complementary features of the surface topography as explained below. The analysis was performed using the "Roughness Analysis" tool of the SPIP application software. 
- $\quad S_{q}$ is the root mean square height of the $z$-values with respect to the reference surface. $S_{q}$ describes the overall height variation of the DEM.

- $S_{d q}$ is the root mean square of the surface gradient. As $S_{d q}$ depends on variations in the local slope, it is sensitive to the short-wavelength components of the surface topography.

- $S_{a l}$ is the auto-correlation length, and is a measure of the spatial distance at which the surface texture becomes statistically different. $S_{a l}$ is calculated as the minimum distance in frequency space at which the auto-correlation function decays to 0.2 in value. Therefore, $S_{a l}$ contains information on the long wavelength components of the surface topography.

\section{Results}

The performance of the SfM reconstruction is illustrated in Figure 5. In Figure 5a,b, the SfM and reference DEM of replication area R1 are shown. Both have been processed as described in Section 2.6. The blue box indicates the subregion used for the ITF analysis. As seen in panel Figure 5a, the SfM DEM captures the main topographic features although the resolution is less than for the reference in Figure $5 \mathrm{~b}$. Although short-wavelength topography variations are missing, holes, edges and the larger glass-fiber structures are visible in the SfM DEM.

(a) SfM

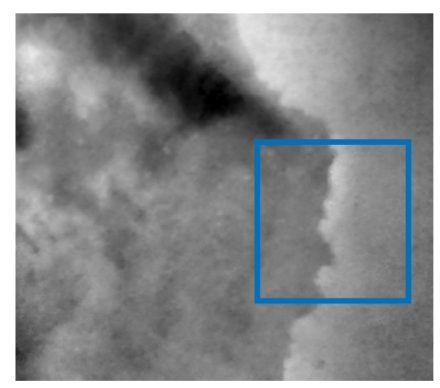

(d) ITF

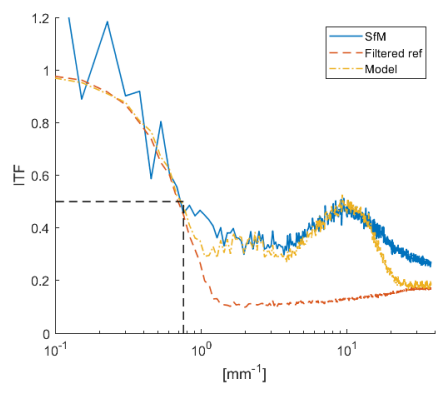

(b) Reference

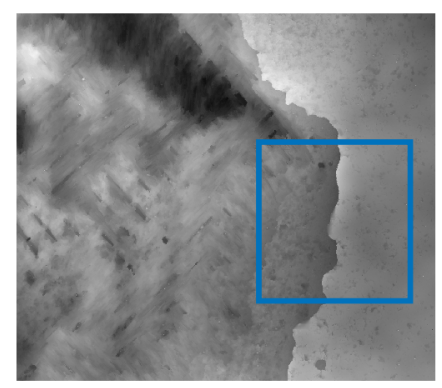

(e) SfM-Reference

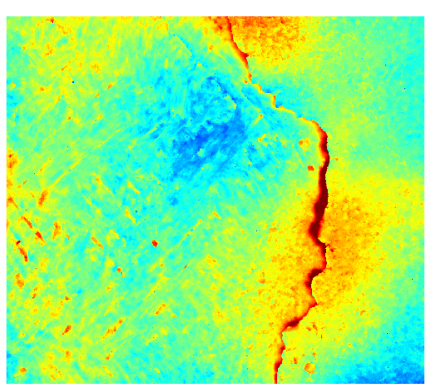

(c) Model

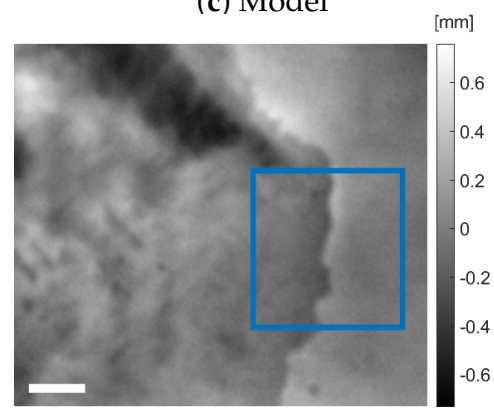

(f) Model-Reference

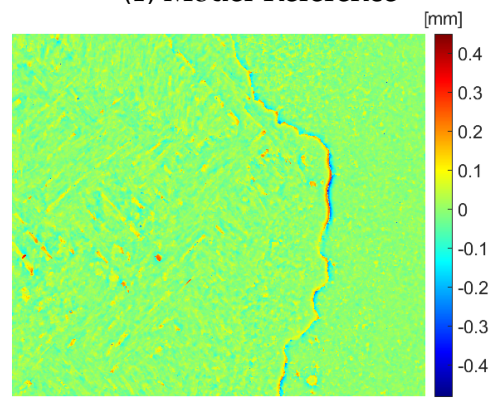

Figure 5. (a) Reference, (b) SfM and (c) model DEM of replication area R1. The blue box indicates the area used for the calculation of ITF50. The scalebar is $5 \mathrm{~mm}$. (d) ITF for SfM and two model curves based on filtering the reference DEM with and without noise added. (e,f) Residual of SfM and model DEM with respect to reference DEM.

The ITF function was calculated from the SfM and Reference DEM of area R1 as described in Section 2.6.1. The ITF was not calculated for R2 and R3 as no height step was present in these areas. In Figure 5d, the ITF function for SfM is shown (blue solid line) with the 50\% value indicated in dashed black lines. As stated in Table 2, the ITF50 spatial wavelength was $1.3 \mathrm{~mm}$.

To validate the shape of the SfM ITF, a model was developed based on the reference DEM. First, the reduced resolution of the SfM reconstruction was approximated by applying a Gaussian low-pass filter to the reference DEM. A filter with a FWHM of $0.65 \mathrm{~mm}$ was used to give the model DEM the same ITF50 value as the SfM. As seen in Figure 5d, the ITF of the filtered reference (dashed red line) matches the long wavelength values of the SfM ITF. However, at higher frequencies the filtered 
reference has lower values than the SfM. In a second step, structured noise centered at $0.5 \mathrm{~mm}$ and $0.1 \mathrm{~mm}$ wavelengths was added (dash-dotted yellow line). The two noise components was constructed through Gaussian low-pass filtering of Gaussian noise with an amplitude selected to match the SfM ITF. In Figure 5c, the model DEM using Gaussian filter and noise added is shown for area R1. Similarly, a model DEM was created for both area R2 and R3 using the same Gaussian FWHM and noise settings.

In Table 2, $\mathrm{CCF}_{\max }$ and RMSD values for both SfM and model DEM are shown for all replication areas. The $\mathrm{CCF}_{\max }$ values for the model were close to 1 for all areas. For SfM, the values were $>0.9$ for both R2 and R3 indicating a very close horizontal spatial resemblance. A slightly smaller value was found for R1. Overall, the $\mathrm{CCF}_{\max }$ values indicate that an accurate scaling of SfM was obtained. As seen in the table, the RMSD values for SfM are between $0.1-0.2 \mathrm{~mm}$, which is several times larger than the model values between $0.03-0.04 \mathrm{~mm}$. This discrepancy is illustrated in the residuals shown in Figure 5e,f. While large differences are observed near sharp edges for both model and SfM DEM, the SfM residuals also contain a waviness that accounts for the larger RMSD value. The waviness has a wavelength in the order of $10 \mathrm{~mm}$ which shows up as large variations in the long wavelength part of the ITF in Figure 5d.

Table 2. Quantitative values for evaluating the SfM reconstruction. $\mathrm{CCF}_{\max }$ and RMSD are included for all three areas R1 to R3 while ITF50 was only calculated for R1.

\begin{tabular}{llll}
\hline Replication Area & R1 & R2 & R3 \\
\hline ITF50 [mm] & 1.3 & & \\
\hline CCF $_{\max }$, SfM & 0.86 & 0.95 & 0.93 \\
CCF $_{\text {max }}$, Model & 0.98 & 0.99 & 0.995 \\
\hline RMSD, SfM [mm] & 0.099 & 0.12 & 0.21 \\
RMSD, Model [mm] & 0.038 & 0.036 & 0.031 \\
\hline
\end{tabular}

To evaluate the surface roughness of the SfM reconstruction, two regions within each of the R1, $\mathrm{R} 2$ and R3 areas were selected as shown with blue solid lines in Figure $6 \mathrm{a}-\mathrm{c}$. Of the six regions named S1 to S6, an extensive erosion of S1 and S3 resulted in a topography dominated by glass-fiber structures while S2, S4, S5 and S6 still had an intact surface coating.

The roughness parameters $S_{q}, S_{d q}$ and $S_{a l}$ were calculated for each of the S1 to S6 regions as described in Section 2.6.2. The roughness values for both SfM and reference are shown in Table 3 and illustrated in scatter plots in Figure 6g-i. Overall, both SfM and reference values show a larger roughness for the eroded S1 and S3 regions than the regions with intact coating. However, when comparing the three roughness parameters on the scatter plots, some differences are clear. Although the SfM values for $S_{q}$ and $S_{a l}$ vary within around 10-20\% of the reference values, the SfM values for $S_{d q}$ are systematically lower than the reference by around $50 \%$. The absolute RMSD deviations for S1 to S6 were $9 \mu \mathrm{m}$ for Sq, 0.5 for $S_{d q}$ and $0.2 \mathrm{~mm}$ for $S_{a l}$.

Three distinctive topographic features were selected in the R1 and R2 areas; Two depressions D1 and D2 (red dashed lines) and a height step H1 (yellow dotted lines) as shown in Figure 6a,b. For all features, the depth and height measurements for the SfM DEM were close to the reference as shown in Table 3. The relative deviations between SfM and reference are less than $16 \%$, and the absolute deviations were less than $0.2 \mathrm{~mm}$ with an RMSD of $0.1 \mathrm{~mm}$. 
(a) R1, Ref

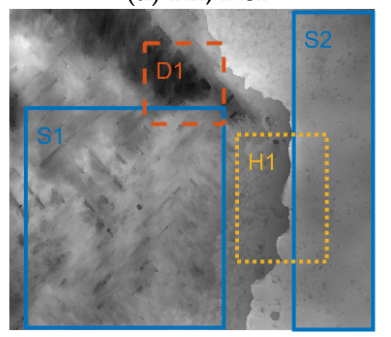

(d) R1, SfM

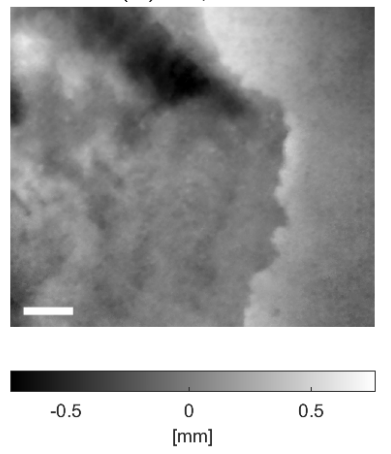

(g) $S_{q}[\mu \mathrm{m}]$

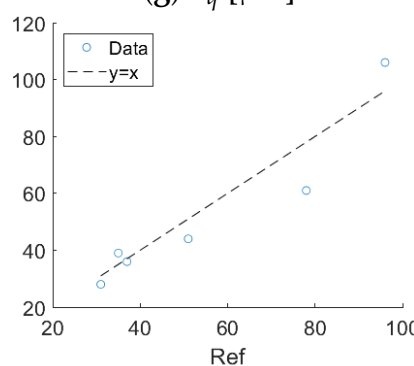

(b) R2, Ref

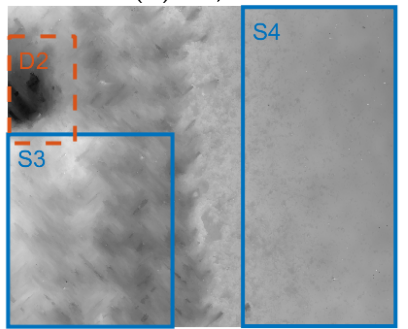

(e) R2, SfM

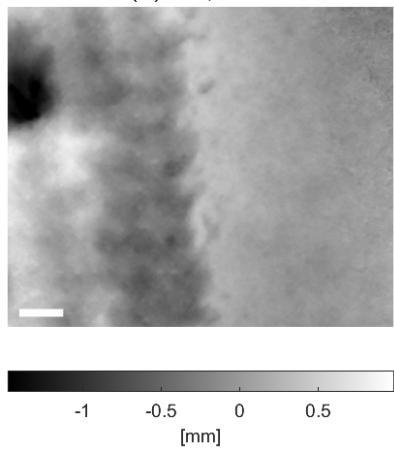

(h) $S_{d q}$

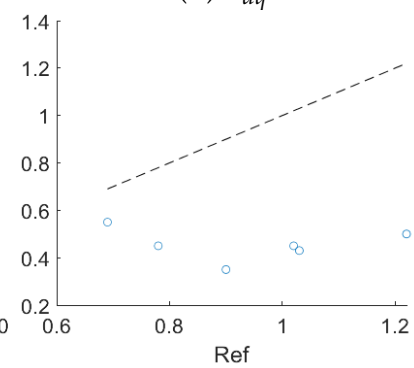

(c) R3, Ref

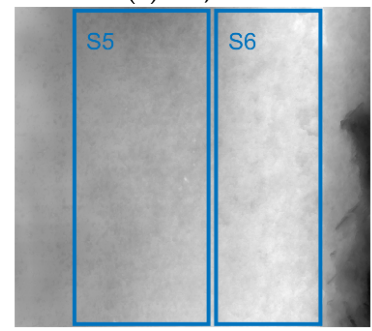

(f) R3, SfM

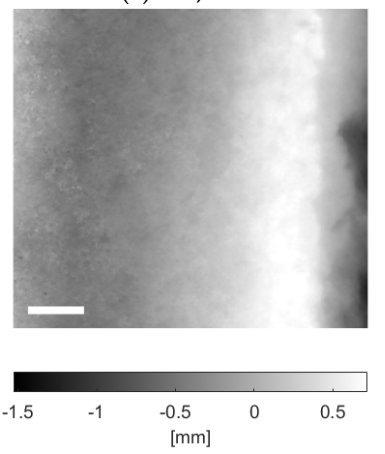

(i) $S_{a l}[\mu \mathrm{m}]$

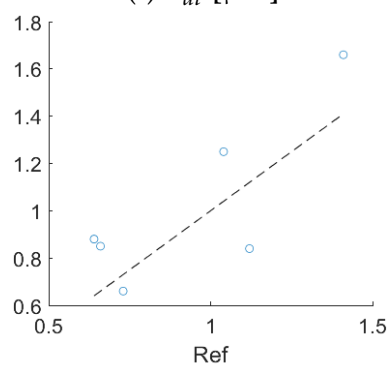

Figure 6. (a-c) Reference and (d-f) SfM DEMs of area R1, R2 and R3, respectively, with prior image processing as described in Section 2.6. Surface roughness regions S1 to S6 are indicated with solid blue lines. Depressions D1, D2 and ridge H1 are indicated with dashed red and dotted yellow lines, respectively. The scalebar is $5 \mathrm{~mm}$. (g-i) Scatter plots of SfM and reference values for $S_{q}, S_{d q}$ and $S_{a l}$, respectively. The dotted line indicates where SfM values are equal to reference values.

Table 3. Quantitative values for surface roughness and topography features. The roughness parameters $S_{q}, S_{d q}$ and $S_{a l}$ for regions S1 to S6 were calculated using an S-filter of $25 \mu \mathrm{m}$ and an L-filter of $10 \mathrm{~mm}$. The depth for depression areas D1 and D2 and height for ridge area H1.

\begin{tabular}{lllllll}
\hline Replication Area & \multicolumn{2}{c}{ R1 } & \multicolumn{2}{c}{ R2 } & \multicolumn{2}{c}{ R3 } \\
\hline & S1 & S2 & S3 & S4 & S5 & S6 \\
\hline$S_{q}$, Ref $[\mu \mathrm{m}]$ & 78 & 31 & 96 & 35 & 37 & 51 \\
$S_{q}$, SfM $[\mu \mathrm{m}]$ & 61 & 28 & 106 & 39 & 36 & 44 \\
\hline$S_{d q}$, Ref & 1.03 & 0.78 & 1.02 & 1.22 & 0.69 & 0.90 \\
$S_{d q}$, SfM & 0.43 & 0.45 & 0.45 & 0.50 & 0.55 & 0.35 \\
\hline$S_{a l}, \operatorname{Ref}[\mathrm{mm}]$ & 1.04 & 1.12 & 1.41 & 0.66 & 0.73 & 0.64 \\
$S_{a l}$, SfM $[\mathrm{mm}]$ & 1.25 & 0.84 & 1.66 & 0.85 & 0.66 & 0.88 \\
\hline & $\mathrm{D} 1$ & $\mathrm{H} 1$ & $\mathrm{D} 2$ & & & \\
\hline$\Delta \mathrm{z}, \operatorname{Ref}[\mathrm{mm}]$ & 0.57 & 0.34 & 1.51 & & & \\
$\Delta \mathrm{z}$, SfM $[\mathrm{mm}]$ & 0.66 & 0.30 & 1.68 & & & \\
\hline
\end{tabular}




\section{Discussion}

The reconstructed SfM displayed a high sharpness and resolution. From the ITF50 value, we have that features down to $1.3 \mathrm{~mm}$ appear sharp. Conversely, the Gaussian FWHM of $0.65 \mathrm{~mm}$ from the model DEM gives a measure of the spatial resolution, i.e., the smallest distinguishable features. The resolution of around $1 \mathrm{~mm}$ is one to two orders of magnitude lower than the GSD of $27 \mu \mathrm{m}$, which is in line with previous high-resolution SfM studies [48,49].

The high value of $\mathrm{CCF}_{\max }$ for the R2 and R3 areas shows a good spatial resemblance between $\mathrm{SfM}$ and reference measurements. The slightly lower value for R1 could either indicate an insufficient resolution or an imperfect co-registration. Since the $\mathrm{CCF}_{\max }$ values for the model DEM were close to 1 , the resolution seems sufficient to preserve the topographic features. The accuracy in co-registrating the DEMs could be limited by the replication molding. Although the replica ensures a high replication accuracy of the surface roughness, the overall shape is not preserved when demolding the replica. Although a levelling was applied in data processing, a waviness was still observed in the residual of the SfM DEM with respect to the reference as seen in Figure 5e. Nonetheless, as the waviness had a wavelength of $10 \mathrm{~mm}$ it did not impact the ITF50 value of $1.3 \mathrm{~mm}$.

Furthermore, as indicated by the model DEM, a rather high noise level was present in the SfM DEM. Some of this may originate from the point-cloud densification or the interpolation when creating the DEM. Varying light intensity may also affect the reconstruction as reported by Wang and Zhang [11]. Further studies are needed to determine the potential for reducing the noise level.

The surface roughness analysis shows relatively good results for SfM measurement of both $S_{q}$ and $S_{a l}$ parameters. The resolution of the SfM reconstruction was sufficient as both $S_{q}$ and $S_{a l}$ are most sensitive to the low spatial frequencies, i.e., structures larger than $1 \mathrm{~mm}$. Similarly, the topographic features D1, H1 and D2 had large spatial widths which ensured good results for the measured depths and heights. In contrast, a poor result was seen for the $S_{d q}$ parameter, which is sensitive to high spatial frequencies, i.e., structures smaller than $1 \mathrm{~mm}$.

The potential for using the $S_{q}$ parameter in quantitative characterization of LER is illustrated in Figure 7. First, the SfM reconstruction was unfolded to a flat shape and extracted as a DEM using CloudCompare. A region centered on the LE was selected as indicated with a box in Figure $7 \mathrm{~b}$. For each $10 \mathrm{~mm} \times 10 \mathrm{~mm}$ square in the region, the $S_{q}$ parameter was calculated and visualized in red in Figure 7c. The strength of the red color indicates the $S_{q}$ value in each square with a lower bound of $20 \mu \mathrm{m}$ (no color) and upper bound of $100 \mu \mathrm{m}$ (color saturated). As seen, the $S_{q}$ values are low for areas with the coating still intact, and high along the eroded leading edge. This indicates the potential for high-resolution SfM for quantitative inspection of LER.

(a) SfM curved shape

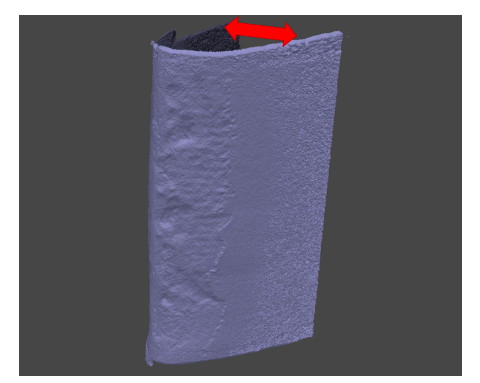

(b) Plane shape

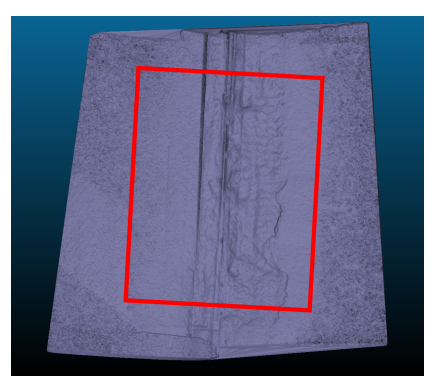

(c) $S_{q}$ visualization

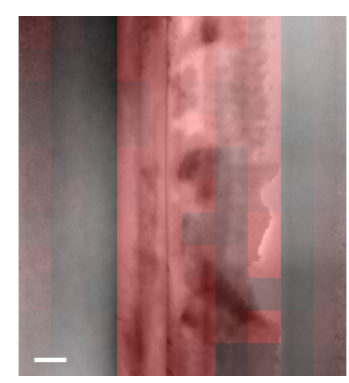

Figure 7. Visualization of LER. The curved blade geometry seen in (a) was unfolded to a flat shape shown in (b) from which a region centered on the LE was selected as indicated by the box. For each $10 \mathrm{~mm} \times 10 \mathrm{~mm}$ square in the region, the $S_{q}$ parameter was calculated. In (c), the strength of the red color indicates the $S_{q}$ value in each square. The scalebar is $10 \mathrm{~mm}$.

For quantitative inspection of the blade erosion, the resolution of the SfM reconstruction needs to match the size of erosion structures, i.e., pits, gauges and delamination. From inspection reports 
of LE erosion structures, Sareen et al. [4] considered pits and gouges with widths down to $0.5 \mathrm{~mm}$ and depths from $0.5 \mathrm{~mm}$ to $3.8 \mathrm{~mm}$. In the study by Gaudern [9], widths down to $2 \mathrm{~mm}$ and depths from $0.1 \mathrm{~mm}$ to $1 \mathrm{~mm}$ were investigated. In both studies, the delamination covered tens of millimeters in width and 1-3 $\mathrm{mm}$ in depth. The lower end of these feature sizes corresponds very closely to the obtained resolution of $\tilde{1} \mathrm{~mm}$. Conversely, as the results of the SfM measurements of topographic features D1, H1 and D2 showed, depths from $0.3 \mathrm{~mm}-1.5 \mathrm{~mm}$ could be successfully measured using high-resolution SfM.

Had the SfM resolution been lower by e.g., using a shorter focal length, the surface roughness and smaller topographic features would not have been visible. This is illustrated in Figure 8 by a model DEM of a SfM acquisition of area R1 with a $2 \mathrm{~m}$ capturing distance using a $100 \mathrm{~mm}$ (Figure 8a) or $35 \mathrm{~mm}$ (Figure $8 \mathrm{~b}$ ) focal length. These settings correspond to a GSD of $0.08 \mathrm{~mm}$ and $0.24 \mathrm{~mm}$, respectively. The model DEMs were created from the R1 reference DEM of Figure $5 b$ by applying a Gaussian low-pass filter with a FWHM of $1.9 \mathrm{~mm}$ and $5.5 \mathrm{~mm}$, respectively. As seen, already for the $100 \mathrm{~mm}$ focal length, the glass-fiber structures are becoming blurred. For the model of a $35 \mathrm{~mm}$ focal length, even the topographic features appear blurred.

In previous studies which applied SfM to reconstruct blade surface, the low resolution would have made a quantification of LER infeasible. In comparison, the settings used by $[11,16]$ resulted in a GSD of around $0.3 \mathrm{~mm}$ which corresponds to the model in Figure 8b. Rather than quantifying the surface topography, they relied on the texture of the reconstruction to locate damages on the blade surface. An advantage of using a lower resolution is that a larger surface area of the turbine blade can be covered in a single reconstruction. Applying high-resolution SfM to reconstruct the full length of a blade would require a very long inspection time and result in a challenging amount of data.

For full blade inspection, 2D images with even lower resolution can be applied which require fewer image acquisitions and a lower acquisition time. However, in this approach the absolute geometry is not obtained, and the LER is not quantified. Instead other methods would be needed to indicate the presence and location of LER such as the deep learning approach used by [13]. In many ways, the proposed high-resolution SfM is complementary to this deep learning approach. By combining both, an initial inspection using low-resolution 2D images would indicate the location of LER on the blades. Afterwards, high-resolution SfM could be applied to quantify the severity of the located erosion, which could be used to estimate the aerodynamic impact. Furthermore, if these inspections were combined with a probabilistic model such as a dynamic Bayesian network model [69], the development of the erosion in time could be estimated. This would provide an input for when to conduct repairs on the blade.

(a) $\mathrm{f}=100 \mathrm{~mm}$

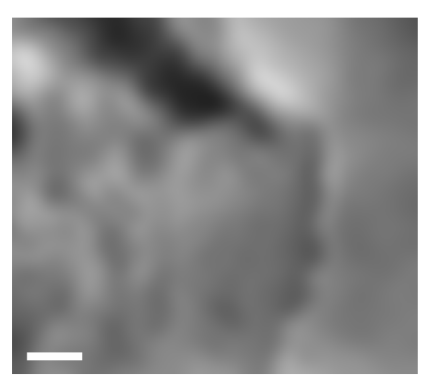

(b) $\mathrm{f}=35 \mathrm{~mm}$

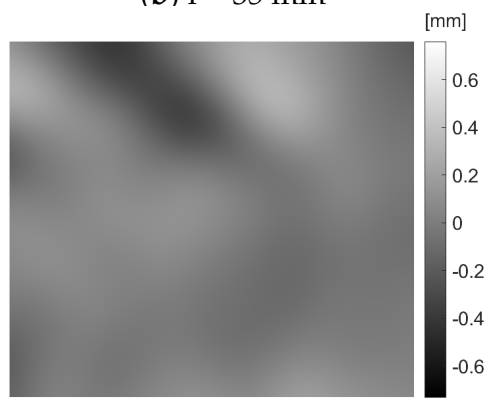

Figure 8. Model DEM of a SfM acquisition of area R1 with (a) $100 \mathrm{~mm}$ and (b) $35 \mathrm{~mm}$ focal length. The model DEMs were created by Gaussian low-pass filtering of the R1 reference DEM of Figure $5 b$ with FWHM of $1.9 \mathrm{~mm}$ and $5.5 \mathrm{~mm}$, respectively. The scalebar is $5 \mathrm{~mm}$.

\section{Conclusions}

This proof-of-principle study demonstrated the successful application of high-resolution SfM to quantify the surface roughness of a decommissioned turbine blade. To better resemble the LE erosion observed from inspections, a severe level of erosion with a large area of delamination was 
applied to the blade. To mimic realistic inspection conditions, the blade was hanged vertically in an outdoor setting, and the SfM image acquisition was conducted handheld to ensure a level of vibrations. Using a $300 \mathrm{~mm}$ focal length and $2 \mathrm{~m}$ distance from the blade, a $1 \mathrm{~mm}$ spatial resolution of the SfM reconstruction was obtained.

To validate the SfM scan, smaller regions of interest were transferred to the lab using replication molding and measured with confocal microscopy. From the co-registered SfM and reference regions, a number of surface roughness parameters and topographic feature size were extracted. The quantitative results of surface roughness and topographic feature sizes displayed sub-mm accuracies. Compared to the reference, the RMSD value was $9 \mu \mathrm{m}$ for the $S_{q}$ roughness using an S-filter of $0.025 \mathrm{~mm}$ and L-filter of $10 \mathrm{~mm}$, while the RMSD value was $0.1 \mathrm{~mm}$ for the depths and heights of topographic features. The results demonstrate the potential for using high-resolution SfM for quantitative measurement of LER on wind turbine blades. Quantitative measurements of LER from blades in operation could aid in creating more realistic CFD models and improve blade inspections.

In future work, a high-resolution SfM inspection using a UAV should be carried out on the blade of a wind turbine in operation. The camera would be mounted in a gantry on the UAV platform to allow for the same poses relative to the blade as in the current study. These settings would allow a more thorough investigation of the effects of vibrations from UAV platform and turbine on the image acquisition and the quality of the 3D reconstructions. In addition, the sensitivity of high-resolution SfM towards surface roughness should be investigated further through measurements on blade surfaces of varying erosion severity. Further studies are also needed on the influence of the texture and color contrast of the blade surface on the quality of the reconstructed surface details.

Author Contributions: The research was conceptualized by C.B.M. and J.G. The methodology was developed by M.S.N., E.K.K. and I.N. who also performed the data collection. Visualization was performed by M.S.N. and I.N. Data analysis and validation was performed by M.S.N. who also wrote the original draft with input from I.N. and E.K.K. C.B.M. and J.G. supervised the research activity and made suggestions for revision. All authors have read and agreed to the published version of the manuscript.

Funding: This work has received funding by the Energy Technology Development and Demonstration Program (project number 64015-0046) under the Danish Energy Agency. M.S.N. and J.G. were also supported by funds from the Danish Agency for Institutions and Educational Grants.

Conflicts of Interest: The authors declare no conflict of interest.

\section{Abbreviations}

The following abbreviations are used in this manuscript:

$\begin{array}{ll}\text { LE } & \text { Leading Edge } \\ \text { LER } & \text { Leading-Edge Roughness } \\ \text { SfM } & \text { Structure-from-Motion } \\ \text { UAV } & \text { Unmanned Aerial Vehicle } \\ \text { CM } & \text { Confocal Microscopy } \\ \text { DEM } & \text { Digital Elevation Model } \\ \text { GSD } & \text { Ground Sampling Distance } \\ \text { ITF } & \text { Instrument Transfer Function } \\ \text { CCF } & \text { Cross-Correlation Function } \\ \text { RMSD } & \text { Root Mean Square Deviation }\end{array}$

\section{References}

1. Zidane, I.F.; Saqr, K.M.; Swadener, G.; Ma, X.; Shehadeh, M.F. On the role of surface roughness in the aerodynamic performance and energy conversion of horizontal wind turbine blades: A review. Int. J. Energy Res. 2016, 40, 2054-2077. [CrossRef]

2. White, E.; Kutz, D.; Freels, J.; Monschke, J.; Grife, R.; Sun, Y.; Chao, D. Leading-Edge Roughness Effects on 63(3)-418 Airfoil Performance. In Proceedings of the 49th AIAA Aerospace Sciences. American Institute of Aeronautics and Astronautics (AIAA), Orlando, FL, USA, 4-7 January 2011. [CrossRef] 
3. Yang, K. Geometry Design Optimization of a Wind Turbine Blade Considering Effects on Aerodynamic Performance by Linearization. Energies 2020, 13, 2320. [CrossRef]

4. Sareen, A.; Sapre, C.A.; Selig, M.S. Effects of leading edge erosion on wind turbine blade performance. Wind Energy 2014, 17, 1531-1542. [CrossRef]

5. Langel, C.M.; Chow, R.; Hurley, O.F.; Van Dam, C.C.P.; Maniaci, D.C.; Ehrmann, R.S.; White, E.B. Analysis of the Impact of Leading Edge Surface Degradation on Wind Turbine Performance. In Proceedings of the 33rd Wind Energy Symposium, Kissimmee, FL, USA, 5-9 January 2015; American Institute of Aeronautics and Astronautics: Reston, VA, USA, 2015. [CrossRef]

6. Han, W.; Kim, J.; Kim, B. Effects of contamination and erosion at the leading edge of blade tip airfoils on the annual energy production of wind turbines. Renew. Energy 2018, 115, 817-823. [CrossRef]

7. Darbandi, M.; Mohajer, A.; Behrouzifar, A.; Jalali, R.; Schneider, G.E. Evaluating the effect of blade surface roughness in megawatt wind turbine performance using analytical and numerical approaches. In Proceedings of the 10th International Conference on Heat Transfer, Fluid Mechanics and Thermodynamics, Orlando, FL, USA, 14-16 July 2014; pp. 800-805.

8. Schramm, M.; Rahimi, H.; Stoevesandt, B.; Tangager, K. The Influence of Eroded Blades on Wind Turbine Performance Using Numerical Simulations. Energies 2017, 10, 1420. [CrossRef]

9. Gaudern, N. A practical study of the aerodynamic impact of wind turbine blade leading edge erosion. J. Phys. Conf. Ser. 2014, 524, 012031. [CrossRef]

10. Tchakoua, P.; Wamkeue, R.; Ouhrouche, M.; Slaoui-Hasnaoui, F.; Tameghe, T.; Ekemb, G. Wind Turbine Condition Monitoring: State-of-the-Art Review, New Trends, and Future Challenges. Energies 2014, 7, 2595-2630. [CrossRef]

11. Wang, L.; Zhang, Z. Automatic Detection of Wind Turbine Blade Surface Cracks Based on UAV-Taken Images. IEEE Trans. Ind. Electron. 2017, 64, 7293-7303. [CrossRef]

12. Peng, L.; Liu, J. Detection and analysis of large-scale WT blade surface cracks based on UAV-taken images. IET Image Process. 2018, 12, 2059-2064. [CrossRef]

13. Shihavuddin, A.; Chen, X.; Fedorov, V.; Nymark Christensen, A.; Andre Brogaard Riis, N.; Branner, K.; Bjorholm Dahl, A.; Reinhold Paulsen, R. Wind Turbine Surface Damage Detection by Deep Learning Aided Drone Inspection Analysis. Energies 2019, 12, 676. [CrossRef]

14. Durdevic, P.; Ortiz-Arroyo, D.; Yang, Z. LiDAR Assisted Camera Inspection of Wind Turbines: Experimental Study. In Proceedings of the 2019 1st International Conference on Electrical, Control and Instrumentation Engineering (ICECIE), Kuala Lumpur, Malaysia, 25 November 2019; IEEE: Piscataway, NJ, USA, 2019; pp. 1-7.

15. Wang, Y.; Yoshihashi, R.; Kawakami, R.; You, S.; Harano, T.; Ito, M.; Komagome, K.; Iida, M.; Naemura, T. Unsupervised anomaly detection with compact deep features for wind turbine blade images taken by a drone. IPSJ Trans. Comput. Vis. Appl. 2019, 11, 1-7. [CrossRef]

16. Zhang, D.; Watson, R.; Dobie, G.; MacLeod, C.; Khan, A.; Pierce, G. Quantifying impacts on remote photogrammetric inspection using unmanned aerial vehicles. Eng. Struct. 2020, 209, 109940. [CrossRef]

17. Sturzenegger, M.; Stead, D. Close-range terrestrial digital photogrammetry and terrestrial laser scanning for discontinuity characterization on rock cuts. Eng. Geol. 2009, 106, 163-182. [CrossRef]

18. Westoby, M.; Brasington, J.; Glasser, N.; Hambrey, M.; Reynolds, J. 'Structure-from-Motion' photogrammetry: A low-cost, effective tool for geoscience applications. Geomorphology 2012, 179, 300-314. [CrossRef]

19. Favalli, M.; Fornaciai, A.; Isola, I.; Tarquini, S.; Nannipieri, L. Multiview 3D reconstruction in geosciences. Comput. Geosci. 2012, 44, 168-176. [CrossRef]

20. Wu, C. VisualSfM: A Visual Structure from Motion System. 2011. Available online: http://ccwu.me/vsfm/ (accessed on 30 July 2020).

21. Sweeney, C.; Hollerer, T.; Turk, M. Theia: A fast and scalable structure-from-motion library. In Proceedings of the 23rd ACM International Conference on Multimedia, Mountain View, CA, USA, 23-27 October 2017; ACM: New York, NY, USA, 2015; pp. 693-696.

22. Agisoft. Metashape. 2010. Available online: http://www.agisoft.com/ (accessed on 20 September 2019).

23. Bentley: ContextCapture. Available online: https://www.bentley.com/en/products/brands/contextcapture (accessed on 6 March 2019).

24. CapturingReality. CapturingReality: Reality Capture. 2016. Available online: https://www.capturingreality. $\mathrm{com} /$ (accessed on 6 May 2020). 
25. Siebert, S.; Teizer, J. Mobile 3D mapping for surveying earthwork projects using an Unmanned Aerial Vehicle (UAV) system. Autom. Constr. 2014, 41,1-14. [CrossRef]

26. Han, K.K.; Golparvar-Fard, M. Appearance-based material classification for monitoring of operation- level construction progress using 4D BIM and site photologs. Autom. Constr. 2015, 53, 44-57. [CrossRef]

27. Tuttas, S.; Braun, A.; Borrmann, A.; Stilla, U. Acquisition and Consecutive Registration of Photogrammetric Point Clouds for Construction Progress Monitoring Using a 4D BIM. PFG-Photogramm. Remote Sens. Geoinf. Sci. 2017, 85, 3-15. [CrossRef]

28. Jahanshahi, M.R.; Masri, S.F.; Padgett, C.W.; Sukhatme, G.S. An innovative methodology for detection and quantification of cracks through incorporation of depth perception. Mach. Vis. Appl. 2013, 24, 227-241. [CrossRef]

29. Chaiyasarn, K.; Kim, T.K.; Viola, F.; Cipolla, R.; Soga, K. Distortion-Free Image Mosaicing for Tunnel Inspection Based on Robust Cylindrical Surface Estimation through Structure from Motion. J. Comput. Civ. Eng. 2016, 30, 4015045. [CrossRef]

30. Stent, S.; Gherardi, R.; Stenger, B.; Soga, K.; Cipolla, R. Visual change detection on tunnel linings. Mach. Vis. Appl. 2016, 27, 319-330. [CrossRef]

31. Masson, J.E.N.; Petry, M.R. Comparison of mesh generation algorithms for railroad reconstruction. In Proceedings of the 2017 IEEE International Conference on Autonomous Robot Systems and Competitions (ICARSC), Coimbra, Portugal, 26-28 April 2017; pp. 266-271.

32. Khaloo, A.; Lattanzi, D. Hierarchical Dense Structure-from-Motion Reconstructions for Infrastructure Condition Assessment. J. Comput. Civ. Eng. 2017, 31, 04016047. [CrossRef]

33. Schöning, J.; Heidemann, G. Evaluation of multi-view 3D reconstruction software. In International Conference on Computer Analysis of Images and Patterns; Springer: Cham, Switzerland, 2015; pp. 450-461.

34. Nikolov, I.; Madsen, C. Benchmarking Close-range Structure from Motion 3D Reconstruction Software Under Varying Capturing Conditions. In Euro-Mediterranean Conference; Springer: Cham, Switzerland, 2016; pp. 15-26.

35. Lowe, D.G. Distinctive image features from scale-invariant keypoints. Int. J. Comput. Vis. 2004, 60, 91-110. [CrossRef]

36. Rublee, E.; Rabaud, V.; Konolige, K.; Bradski, G. ORB: An efficient alternative to SIFT or SURF. In Proceedings of the 2011 International Conference on Computer Vision, Barcelona, Spain, 6-13 November 2011; pp. 2564-2571.

37. Wu, C. Towards linear-time incremental structure from motion. In Proceedings of the 2013 International Conference on 3D Vision-3DV, Seattle, WA, USA, 29 June-1 July 2013; IEEE: Piscataway, NJ, USA, 2013; pp. 127-134.

38. Smith, M.W.; Carrivick, J.L.; Quincey, D.J. Structure from motion photogrammetry in physical geography. Prog. Phys. Geogr. Earth Environ. 2016, 40, 247-275. [CrossRef]

39. D'Amico, N.; Yu, T. Accuracy analysis of point cloud modeling for evaluating concrete specimens. In Proceedings of the SPIE Smart Structures and Materials+ Nondestructive Evaluation and Health Monitoring, Portland, OR, USA, 25-29 March 2017; p. 101691D.

40. Micheletti, N.; Chandler, J.H.; Lane, S.N. Investigating the geomorphological potential of freely available and accessible structure-from-motion photogrammetry using a smartphone. Earth Surf. Process. Landforms 2015, 40, 473-486. [CrossRef]

41. Smith, M.W.; Vericat, D. From experimental plots to experimental landscapes: Topography, erosion and deposition in sub-humid badlands from Structure-from-Motion photogrammetry. Earth Surf. Process. Landforms 2015, 40, 1656-1671. [CrossRef]

42. Micheletti, N.; Chandler, J.H.; Lane, S.N. Structure from Motion (SfM) Photogrammetry. In Geomorphological Techniques, Online ed.; British Society for Geomorphology Geomorphological Techniques; 2015; Chapter 2.2, pp. 1-12.

43. Harwin, S.; Lucieer, A. Assessing the Accuracy of Georeferenced Point Clouds Produced via Multi-View Stereopsis from Unmanned Aerial Vehicle (UAV) Imagery. Remote Sens. 2012, 4, 1573-1599. [CrossRef]

44. Kersten, T.P.; Lindstaedt, M. Image-based low-cost systems for automatic 3D recording and modelling of archaeological finds and objects. In Euro-Mediterranean Conference; Springer: Berlin/Heidelberg, Germany, 2012; pp. 1-10. 
45. Thoeni, K.; Giacomini, A.; Murtagh, R.; Kniest, E. A comparison of multi-view 3D reconstruction of a rock wall using several cameras and a Laser scanner. Int. Arch. Photogramm. Remote Sens. Spat. Inf. Sci.-ISPRS Arch. 2014, 40, 573-580. [CrossRef]

46. James, M.R.; Robson, S. Straightforward reconstruction of 3D surfaces and topography with a camera: Accuracy and geoscience application. J. Geophys. Res. Earth Surf. 2012, 117. [CrossRef]

47. Goetz, J.; Brenning, A.; Marcer, M.; Bodin, X. Modeling the precision of structure-from-motion multi-view stereo digital elevation models from repeated close-range aerial surveys. Remote Sens. Environ. 2018, 210, 208-216. [CrossRef]

48. Tavani, S.; Corradetti, A.; Billi, A. High precision analysis of an embryonic extensional fault-related fold using 3D orthorectified virtual outcrops: The viewpoint importance in structural geology. J. Struct. Geol. 2016, 86, 200-210. [CrossRef]

49. Corradetti, A.; McCaffrey, K.; De Paola, N.; Tavani, S. Evaluating roughness scaling properties of natural active fault surfaces by means of multi-view photogrammetry. Tectonophysics 2017, 717, 599-606. [CrossRef]

50. Hansen, H.; Hocken, R.; Tosello, G. Replication of micro and nano surface geometries. CIRP Ann.-Manuf. Technol. 2011, 60, 695-714. [CrossRef]

51. Nilsson, L.; Ohlsson, R. Accuracy of replica materials when measuring engineering surfaces. Int. J. Mach. Tools Manuf. 2001, 41, 2139-2145. [CrossRef]

52. Gasparin, S..; Hansen, H.N.; Tosello, G. Traceable Surface Characterization Using Replica Moulding Technology. In proceedings of the 13th International Conference on Metrology and Properties of Engineering Surfaces, Twickenham, UK, 12-15 April 2011; pp. 310-315

53. Liu, Y.C.; Ling, C.Y.; Malcolm, A.A.; Dong, Z.G. Accuracy of Replication for Non-Destructive Surface Finish Measurement; In proceedings of the Singapore International NDT Conference \& Exhibition, Singapore, 3-4 November 2011; pp. 3-4.

54. Walton, K.; Fleming, L.; Goodhand, M.; Racasan, R.; Zeng, W. High fidelity replication of surface texture and geometric form of a high aspect ratio aerodynamic test component. Surf. Topogr. Metrol. Prop. 2016, 4, 025003. [CrossRef]

55. Baruffi, F.; Parenti, P.; Cacciatore, F.; Annoni, M.; Tosello, G. On the Application of Replica Molding Technology for the Indirect Measurement of Surface and Geometry of Micromilled Components. Micromachines 2017, 8, 195. [CrossRef]

56. Kumar, C.; Palacios, A.; Surapaneni, V.A.; Bold, G.; Thielen, M.; Licht, E.; Higham, T.E.; Speck, T.; Le Houérou, V. Replicating the complexity of natural surfaces: Technique validation and applications for biomimetics, ecology and evolution. Philos. Trans. R. Soc. A Math. Phys. Eng. Sci. 2019, 377. [CrossRef]

57. Bak, C.; Gaunaa, M.; Olsen, A.S.; Kruse, E.K. What is the critical height of leading edge roughness for aerodynamics. J. Phys. Conf. Ser. 2016, 753, 022023. [CrossRef]

58. Schöning, J.; Heidemann, G. Taxonomy of 3D Sensors-A Survey of State-of-the-Art Consumer 3D-Reconstruction Sensors and their Field of Applications; In Proceedings of the 11th International Joint Conference on Computer Vision, Imaging and Computer Graphics Theory and Applications, VISIGRAPP (3: VISAPP), Rome, Italy, 27-29 February 2016; SciTePress Digital Library: Setubal, Portugal, 2016; pp. 194-199.

59. Nikolov, I.; Madsen, C. Performance Characterization of Absolute Scale Computation for 3D Structure from Motion Reconstruction. In Proceedings of the 14th International Joint Conference on Computer Vision, Imaging and Computer Graphics Theory and Applications, Visigrapp (3: VISAPP), Prague, Czech Republic, 25-27 February 2019; SciTePress Digital Library: Setubal, Portugal, 2019; pp. 884-891.

60. Girardeau-Montaut, D. CloudCompare. Available online: http://www.cloudcompare.org/ (accessed on 6 March 2019).

61. Struers 2010 RepliSet Technical Data Sheet. Available online: https://www.struers.com/en/Products/ Materialographic-analysis/Materialographic-analysis-equipment/Replication-system (accessed on 6 March 2020).

62. Jolivet, S.; Mezghani, S.; El Mansori, M. Multiscale analysis of replication technique efficiency for 3D roughness characterization of manufactured surfaces. Surf. Topogr. Metrol. Prop. 2016, 4, 035002. [CrossRef]

63. PLU NEOX Confocal Microscope. Available online: https://www.sensofar.com/sensofar-introduces-theirmost-advanced-optical-3d-profiler-plu-neox/\# (accessed on 6 March 2020). 
64. Scanning Probe Image Processor (SPIP). Available online: https: / /www.imagemet.com/products/spip / (accessed on 6 March 2020).

65. de Groot, P.; de Lega, X.C. Interpreting interferometric height measurements using the instrument transfer function. In Fringe 2005; Springer: Berlin/Heidelberg, Germany, 2006; pp. 30-37. [CrossRef]

66. Song, J.; Vorburger, T.; Ma, L.; Libert, J.; Ballou, S. A metric for the comparison of surface topographies of standard reference material (SRM) bullets and casings. In Proceedings of the 20th Annual ASPE Meeting, ASPE 2005, Norfolk, VA, USA, 9-14 October 2005.

67. ISO 25178-3(2012) Geometrical Product Specifications (GPS)—Surface Texture: Areal—Part 3: Specification Operators. Available online: https:/ / www.iso.org/standard/42895.html (accessed on 5 March 2020).

68. ISO 25178 Geometrical Product Specifications (GPS)—Surface Texture: Areal—Part 2: Terms, Definitions and Surface Texture Parameters. Available online: https:/ /www.iso.org/standard/42785.html (accessed on 5 March 2020).

69. Nielsen, J.S.; Sørensen, J.D. Bayesian estimation of remaining useful life for wind turbine blades. Energies 2017, 10, 664. [CrossRef]

(c) 2020 by the authors. Licensee MDPI, Basel, Switzerland. This article is an open access article distributed under the terms and conditions of the Creative Commons Attribution (CC BY) license (http:/ / creativecommons.org/licenses/by/4.0/). 